UDC 504.064.2.001.18

LBC 20.18

\title{
DANDELION TARAXACUM OFFICINALE L. AS A PROMISING TOOL FOR BIO-DIAGNOSTICS OF THE STATE OF THE URBAN ENVIRONMENT
}

\author{
Nikolay V. Onistratenko \\ Volgograd State University, Volgograd, Russian Federation \\ Xenia I. Roubanova \\ Volgograd State University, Volgograd, Russian Federation
}

\begin{abstract}
The need to expand the list of organisms used in environmental biodiagnostics arises from the variety of pollutants and types of man-made effects on the biosphere. The choice of available test organism should be based on easily detectable and differentiable sensitivity to factors, high reproducibility of seed material, alignment of the genetic line used by the gene pool and phenotype. The paper presents the results of the soil contamination of urban agglomeration study by the bioindication and biotesting method using a dandelion as a bioindicator plant and a test organism. Within the study, the generation of dandelion was obtained and investigated for applicability in biotesting. During the first stage of the study, soil samples were taken in the influence zone of VOAO Khimprom and near the $2^{\text {nd }}$ Prodol'naya avenue of Volgograd. Germination of dandelion seeds showed noticeable differences in growth rates both in comparison with control and in comparison, of prototypes with each other. At the end of the first stage, numerous apomictic seed offspring were obtained to excrete the aligned genetic lineage of test organisms. The expansion of the list of contaminated locations by counting the territories adjacent to the VMK Krasnyi Oktyabr' showed the detected differentiated physiological reaction of test organisms grown in experimental soil samples. The results of the study confirm the postulate on soil contamination of urban locations with physiologically active pollutants and also characterize the used plant as a sensitive and easily reproducible test organism under artificial conditions. During the two-year experiment the possibility of selecting the genetic lineage Taraxacum officinale with predictable and monotonous properties was proved due to the tendency of this species to apomixis.
\end{abstract}

Key words: bioassay, dandelion, test organism, pollutant, germination.

Citation. Onistratenko N.V., Roubanova X.I. Dandelion Taraxacum officinale L. As a Promising Tool for BioDiagnostics of the State of the Urban Environment. Prirodnye sistemy i resursy [Natural Systems and Resources], 2021, vol. 11, no. 3, pp. 14-21. DOI: https://doi.org/10.15688/nsr.jvolsu.2021.3.2

УДК 504.064.2.001.18 \section{КАК ПЕРСПЕКТИВНЫЙ ИНСТРУМЕНТ БИОДИАГНОСТИКИ СОСТОЯНИЯ} ГОРОДСКОЙ СРЕДЫ

\author{
Николай Владимирович Онистратенко \\ Волгоградский государственный университет, г. Волгоград, Российская Федерация \\ Ксения Игоревна Рубанова \\ Волгоградский государственный университет, г. Волгоград, Российская Федерация
}

Аннотация. Потребность в расширении перечня организмов, используемых в биодиагностике состояния окружающей среды, закономерно вытекает из разнообразия поллютантов и видов техногенного воздействия 
на биосферу. Выбор доступного тест-организма должен основываться на легко определяемой и дифференцируемой чувствительности к факторам, высокой воспроизводимости семенного материала, выровненности используемой генетической линии по генофонду и фенотипу. В работе представлены результаты исследования загрязненности почв городской агломерации методом биоиндикации и биотестирования с применением одуванчика лекарственного в качестве растения-биоиндикатора и тест-организма. Также в ходе исследования получено и исследовано на применимость в биотестировании поколение одуванчика лекарственного. В ходе первого этапа исследования образцы почв отбирались в зоне влияния ВОАО «Химпром» и вблизи 2-й Продольной магистрали Волгограда. Проращивание семян одуванчика показало ощутимые различия ростовых показателей как в сравнении с контролем, так и в сравнении опытных образцов между собой. В конце первого этапа было получено многочисленное апомиктическое семенное потомство для выведения выровненной генетической линии тест-организмов. Расширение перечня загрязненных локаций за счет территорий, прилегающих к ВМК «Красный Октябрь», показало выявляемую дифференцированную физиологическую реакцию тест-организмов, выращиваемых в опытных образцах почвы. Результаты исследования подтверждают постулат о загрязнении почв городских локаций физиологически активными поллютантами, а также характеризуют использованное растение как чувствительный и легко воспроизводимый в искусственных условиях тест-организм. В ходе двухлетнего опыта была доказана возможность селекции генетической линии Taraxacum officinale с прогнозируемыми и однообразными свойствами, что обусловлено склонностью данного вида к апомиксису.

Ключевые слова: биотестирование, одуванчик лекарственный, тест-организм, поллютант, всхожесть.

Цитирование. Онистратенко Н. В., Рубанова К. И. Одуванчик лекарственный Taraxacum officinale L. как перспективный инструмент биодиагностики состояния городской среды // Природные системы и ресурсы. -2021. - Т. 11, № 3. - C. 14-21. - DOI: https://doi.org/10.15688/nsr.jvolsu.2021.3.2

\section{Введение}

Проведение экологического мониторинга состояния окружающей среды может осуществляться и с применением фитоиндикации загрязнений. В условиях экологического неблагополучия риск существует для всех живых организмов, при этом растения раньше, чем животные, реагируют на смену условий среды обитания [5]. Выбор растения-индикатора для проведения биотестирования имеет первостепенное значение по причине видовой специфики реакции на различные поллютанты [11]. Тест-растения обозначают собой те самые биологические элементы, которые составляют тест-систему [6; 13].

Почвы в совокупности с растениями-индикаторами аккумулируют значительную часть загрязнений, поступающих из атмосферного воздуха, в результате чего они служат индикаторами техногенной нагрузки на окружающую среду [8]. Адсорбция загрязняющих веществ и их удержание являются основными экологическими функциями почвы, что влияет на ее продуктивность и пригодность для произрастания различных растений, также она выполняет важные средообразующие функции [17].
В 2019 г., по данным Управления Федеральной службы по надзору в сфере природопользования (Росприроднадзор) по Волгоградской области, масса выбросов загрязняющих веществ в атмосферу по региону от стационарных источников составила более 80 тыс. т, а выбросы в атмосферу от автотранспорта по данным Единой межведомственной информационно-статистической системы (ЕМИСС) составили 91,4 тыс. т [3].

Научный и практический интерес представляет проведение мониторинга окружающей среды на содержание различных форм загрязнений в почвах вблизи источников антропогенного воздействия на экосистемы [4; $12 ; 15]$. Депонирующая роль почв во взаимодействии с растительностью переходит в метаболическую роль, что выражается в преобразовании поллютантов в более биодоступные формы [2].

Получение растительного маркера, отвечающего на конкретные загрязнения, способствует своевременному определению их присутствия в окружающей среде. Выведение потомственной линии однообразных особей для использования их в качестве тестобъектов позволит получить точные резуль- 
таты, а их применение будет наиболее эффективным при биомониторинге.

\section{Материалы и методы}

Одуванчик лекарственный (Taraxacum officinale L.) выбран в качестве биоиндикатора ввиду повсеместной распространенности и хорошей изученности. Taraxacum officinale активно применяется в экологическом мониторинге, особенно часто его используют в качестве индикатора тяжелых металлов. Выбор одуванчика именно для индикации тяжелых металлов обусловлен тем, что металлы накапливаются в его листьях и корневой системе [16; 17].

В качестве методики для проведения биотестирования с использованием одуванчика лекарственного (Taraxacum officinale) нами был выбран метод определения фитотоксичности по ингибированию прорастания семян и роста проростков [10]. В используемом методе для развернутой оценки влияния загрязнения почвы учитывается ряд показателей, принятых в семеноводстве, к которым относятся всхожесть, энергия прорастания, дружность прорастания и скорость прорастания. Фитотестирование как способ оценки применяется в природоохранной практике для оценки экологического состояния окружающей среды, уровень фитотоксичности почв отмечается при накоплении тяжелых металлов в количествах, превышающих ПДК [7; 14].

Под всхожестью понимают число проросших семян, выраженное в процентах от общего количества высаженных семян.

К энергии прорастания относят число семян, проросших за первые трое суток, выраженное в процентах от общего количества семян, взятых для проращивания [9].

Дружность прорастания представляет собой средний процент семян, проросших за первые сутки прорастания:

$$
\text { Д }=\frac{\Pi}{\mathrm{A}},
$$

где Д - дружность прорастания; П - полная всхожесть; А - число дней прорастания.

Скорость прорастания - это сумма средних чисел семян, прорастающих ежедневно:

$$
\mathrm{C}=\mathrm{a}+\frac{6}{2}+\frac{\mathrm{B}}{3}+\ldots+\frac{n}{n}
$$

где С - скорость прорастания; а, б, в, $\ldots, n$ - число семян, проросших за первые, вторые, третьи и последующие сутки.

Также нами применялся метод определения всхожести семян, регламентируемый ГОСТ 12038-84 [1]. Для работы использовалась усредненная выборка 10 семян, полученная методом квартования из 100 семян. Семена раскладываются на трех слоях увлажненной фильтровальной бумаги в одноразовые контейнеры.

Для первого этапа исследования, проводимого в осенний период 2019 г., применялись семена Taraxacum officinale, собранные с плодоносящего одуванчика, произрастающего на территории города Волгограда. Семена высаживались в предварительно отобранную почву точек с неблагоприятным статусом, а также в месте с минимальным антропогенным воздействием на территории города Волгограда и Волгоградской области: на территории химического предприятия (BОАО «Химпром»), на участке рядом с дорогой (2-я Продольная магистраль в Кировском районе города), в степи (Ольховский район, Волгоградская область). Контрольная выборка высеивалась на перлит. Для эксперимента был произведен отбор почвы с одинаковой глубины 20-30 см. Масса невысушенной почвы с каждой точки составила 1 килограмм. В каждую навеску почвы и перлит в начале эксперимента было высеяно по 20 семян. Образцы почвы и семена растений собирались в сентябре 2019 года.

По завершению опыта по определению фитотоксичности методом оценки ингибирования прорастания семян и роста проростков были выбраны наиболее типичные особи, от которых в конце весны 2020 г. был собран урожай семян.

На втором этапе исследования, который проводился осенью 2020 г., отобранные семена использовались для проверки следующих почвенных образцов: условно чистая почва, отобранная в степной зоне (Ольховский район, Волгоградская область); почвы загрязненной зоны химического предприятия (ВОАО «Химпром»), участка рядом с дорогой (2-я Продольная магистраль в Кировском районе го- 
рода) и с территории промышленного объекта (ВМК «Красный Октябрь»).

\section{Результаты и обсуждение}

В ходе проращивания семян в рамках первого этапа исследования было произведено сравнение ростков по внешнем признакам (рис. 1). При сравнении ростков, проросших в исследуемой почве к третьему дню наблюдения, можно отметить, что наиболее интенсивно проросли семена, высаженные в степную почву; семена, высаженные в перлит, проросли чуть позже, чем семена в степной зоне (рис. 1a). К шестому дню наблюдения можно отметить, что у особей, проращиваемых в почве степной зоны, в отличие от других, появились третьи листочки, более заостренные (рис. 1б). На двенадцатый день наблюдений отмечено резкое ускорение роста у особей, выращиваемых в почве, отобранной рядом с химическим предприятием и автомагистралью (рис. 18). Такую парадоксальную реакцию можно объяснить тем, что находящиеся в данной почве загрязняющие вещества могли выступить в роли ростовых стимуляторов. На двенадцатый день все проросшие ростки

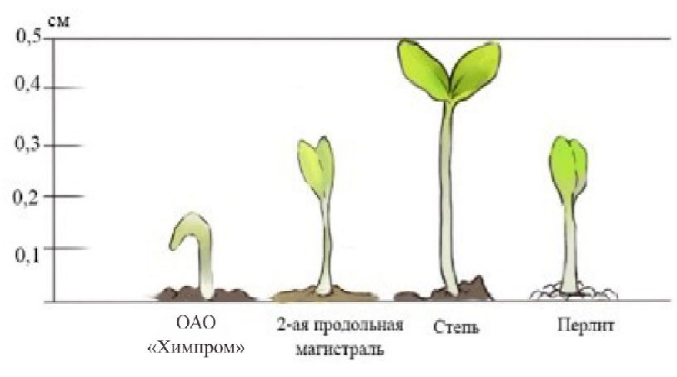

a) третий день эксперименма

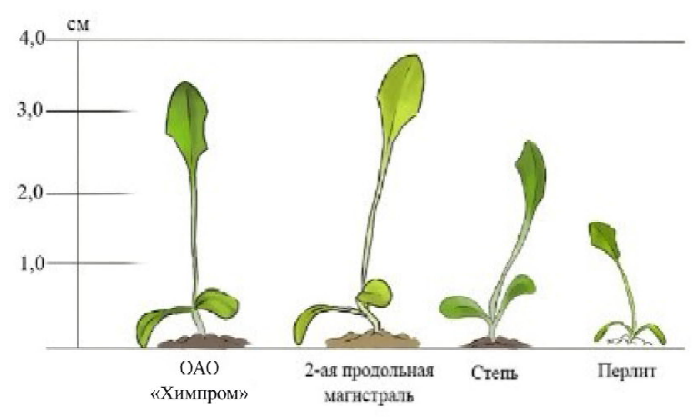

в) двенафиатьй день эксперичента имели по три листочка, один из которых имел уже четкую вытянутую форму (то есть был первым настоящим листом в обрамлении двух семядольных листочков). К последнему дню наблюдения одуванчики, выращиваемые в почве, отобранной рядом с дорогой, более вытянуты по сравнению с другими ростками (рис. 12). Наименьший прирост к концу наблюдения был отмечен у особей, выращиваемых в чистом перлите. У более крупных ростков стали появляться последующие листья характерной для вида формы.

В ходе развернутой оценки влияния загрязнения почвы были определены всхожесть и энергия прорастания семян в отобранной почве. По формулам (1) и (2) были рассчитаны дружность прорастания и скорость прорастания семян.

Для определения всхожести семян было учтено количество семян, проросших к последнему дню наблюдения. Таким образом, можно отметить, что минимальные всхожесть и энергия прорастания отмечены у семян, выращиваемых в почве, отобранной рядом с дорогой. Максимальным процентом дружности прорастания обладают семена, выращиваемые в чистом перлите (см. табл. 1).

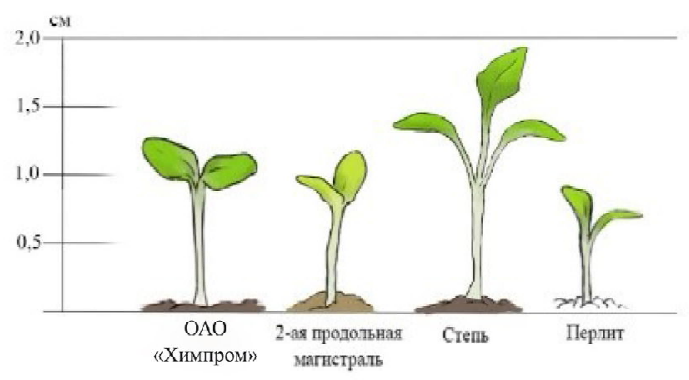

б) иестой день эксперименma

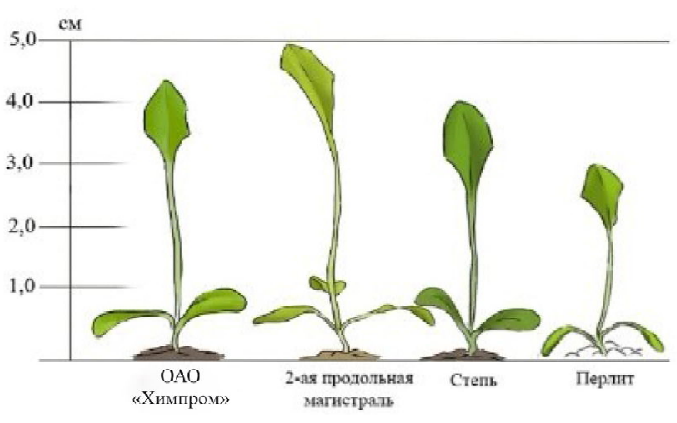

c) dвадиать первый dень зксперимента

Рис. 1. Размеры ростков Taraxacum officinale в первом эксперименте 


\section{ЭКОЛОГИя И БИОЛОГИЯ}

Сравнивая ростки Taraxacum officinale в ходе второго этапа исследования (рис. 2), можно отметить, что семена, высаженные в почву, характеризующуюся минимальным антропогенным воздействием, в первые дни прорастали более интенсивно, чем семена, высаженные в загрязненную почву (рис. $2 a$ ).

К девятому дню у ростков появились первые настоящие заостренные листочки, за исключением образцов проращиваемых в почве, отобранной на территории ОАО «Химпром» (рис. 2б). Это связано с запоздалой всхожестью семян, проращиваемых в данной почве, по сравнению с другими образцами. К двадцать седьмому дню у всех проростков имеется по три листа (один настоящий лист и два семядольных). Также отмечено, что рос- тки в почве, подвергшейся действию транспортных поллютантов, характеризовались менее насыщенной окраской по сравнению с другими образцами. Это сигнализирует о меньшем содержании хлорофилла. У большинства особей, выращиваемых в почвах, отобранных в условно чистом месте и рядом со 2-й Продольной магистралью Волгограда, к этому времени имеется уже более трех листков (рис. 2в).

Оценка влияния загрязнения на ростовые процессы одуванчика лекарственного в ходе второго этапа проводились аналогичным первому этапу образом по тем же формулам (1) и (2). Семена, пророщенные в степной почве, значительно превосходили другие образцы по энергии прорастания. Се-

Таблица 1

Показатели развернутой оценки влияния загрязнения почвы на прорастание семян за 2019 год

\begin{tabular}{|c|c|c|c|c|}
\hline \multirow[b]{2}{*}{ Показатели } & \multicolumn{4}{|c|}{ Образцы отобранной почвы } \\
\hline & ОАО «Химпром» & $\begin{array}{c}\text { 2-я Продольная } \\
\text { магистраль }\end{array}$ & Степь & Чистый перлит \\
\hline Всхожесть семян & $80 \%$ & $30 \%$ & $90 \%$ & $90 \%$ \\
\hline Энергия прорастания семян & $65 \%$ & $30 \%$ & $80 \%$ & $85 \%$ \\
\hline Дружность прорастания семян & $15 \%$ & $5 \%$ & $8,5 \%$ & $30 \%$ \\
\hline Скорость прорастания семян & 5,1 & 2,3 & 6,1 & 6,6 \\
\hline
\end{tabular}
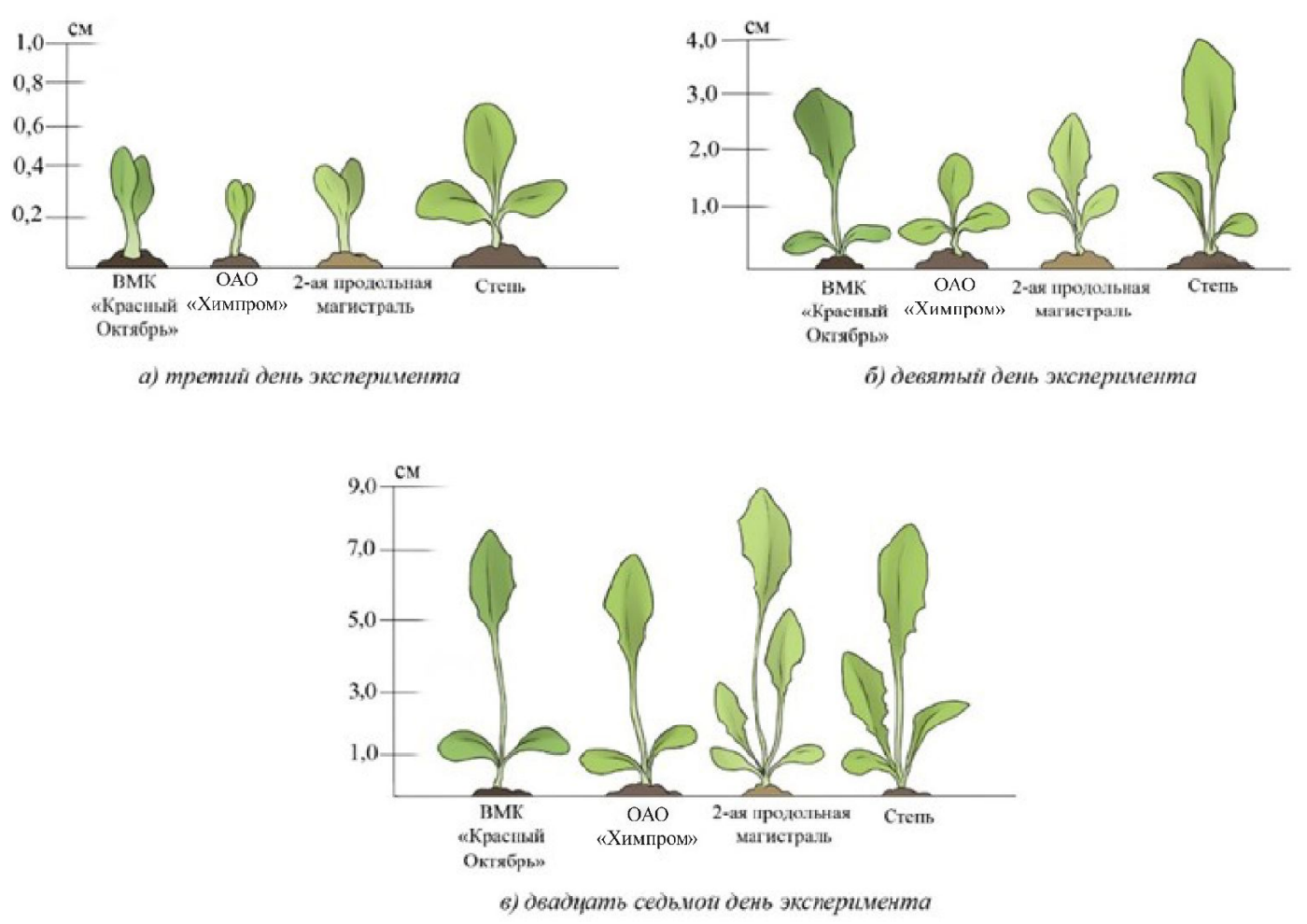

Рис. 2. Размеры ростков Taraxacum officinale во втором эксперименте 
мена, выращиваемые в почве, отобранной рядом с дорогой, отличаются энергией прорастания от семян, выращиваемых в почвах, отобранных рядом с предприятиями, и характеризуются большой всхожестью (табл. 2).

Таким образом, результаты двухэтапного опыта подтверждают общую тенденцию снижения показателей динамики прорастания семян и физиологического благополучия проростков одуванчика лекарственного. Также следует отметить повторяемую дифференцированную реакцию на различия в количественных и качественных характеристиках загрязнения обследуемой среды, что подтверждает возможность использования растения в качестве тест-организма в биодиагностической практике.

\section{Заключение}

В результате всех проведенных исследований и наблюдений нами были сделаны выводы о перспективности применения одуванчика лекарственного Taraxacum officinale в качестве биоиндикатора для проведения экологического мониторинга. Исследование загрязненных почвенных образцов подтвердило, с одной стороны, физиологически значимый уровень техногенной токсичности почв городской агломерации, с другой - возможность использования одуванчика лекарственного в качестве тест-организма благодаря его хорошо дифференцируемой реакции на поллютанты. Также к материальным результатам исследования следует отнести получение семенного фонда для дальнейшей селекции устойчивой линии с выровненным генофондом и фенотипической реакцией на воздействия в ходе биотестирования.

\section{СПИСОК ЛИТЕРАТУРЫ}

1. ГОСТ 12038-84. Межгосударственный стандарт. Семена сельскохозяйственных культур. Методы определения всхожести (утв. и введен в действие Постановлением Госстандарта СССР от 19.12.1984 № 4710) (ред. от 01.03.1995. с изм. от 01.10.1999). Электрон. текстовые дан. - Режим доступа: http:// www.consultant.ru/search/?q=\%D0\%93\%D0\% 9E\%D0\%A1\%D0\%A2+12038-84. - Загл. с экрана.

2. Влияние присутствия подвижных форм Zn, $\mathrm{Cu}, \mathrm{Ni}$ на функционирование системы «почва-микробиота-растение» в зерновых агроценозах / Е. А. Иванцова [и др.] // Экология и промышленность России. - 2018. - Т. 22, № 11. - С. 56-59. - DOI: https://doi.org/10.18412/1816-0395-2018-11-56-59.

3. Доклад «О состоянии окружающей среды Волгоградской области в 2019 году» / редкол.: В. Е. Сазонов [и др.]; Ком. природ. ресурсов, лесн. хоз-ва и экологии Волгогр. обл. - Волгоград : ТЕМПОРА, 2020. - $300 \mathrm{c}$.

4. Заикина, В. Н. Способы трансформации тяжелых металлов в почвах агломерации ВолгоградВолжский / В. Н. Заикина, А. А. Околелова, М. П. Корчагина // Известия высших учебных заведений. Поволжский регион. Естественные науки. 2018. - Vol. 2, № 22. - C. 52-62. - DOI: https://doi.org/ 10.21685/2307-9150-2018-2-5.

5. Ильин, В. Б. Тяжелые металлы и неметаллы в системе почва-растение : монография / В. Б. Ильин ; отв. ред. А. И. Сысо ; Рос. акад. наук. Сиб. отдние; Ин-т почвоведения и агрохимии. - Новосибирск : СО РАН, 2012. -220 с.

6. Межневский, В. Н. Растения-индикаторы / В. Н. Межневский. - М. : АСТ, 2004. - 76 с.

7. Плеханова, И. О. Применение методов биотестирования при оценке экологического состояния почв / И. О. Плеханова, О. А. Золотарёва, И. Д. Тарасенко // Вестник Московского университета. Серия 17, Почвоведение. - 2018. - № 4. C. $36-46$.

8. Почвенный покров как индикатор полиметаллического загрязнения приземного слоя атмосферного воздуха г. Казани / Ю. А. Тунакова [и др.]

Таблииа 2

Показатели развернутой оценки влияния загрязнения почвы на прорастание семян за 2020 год

\begin{tabular}{|c|c|c|c|c|}
\hline \multirow[b]{2}{*}{ Показатели } & \multicolumn{4}{|c|}{ Образцы отобранной почвы } \\
\hline & $\begin{array}{c}\text { ВМК «Красный } \\
\text { Октябрь» }\end{array}$ & ОАО «Химпром» & $\begin{array}{c}\text { 2-я Продольная } \\
\text { магистраль }\end{array}$ & Степь \\
\hline Полная всхожесть семян & $60 \%$ & $50 \%$ & $60 \%$ & $70 \%$ \\
\hline Энергия прорастания семян & $20 \%$ & $15 \%$ & $30 \%$ & $45 \%$ \\
\hline Дружность прорастания семян & $10 \%$ & $6,25 \%$ & $8,6 \%$ & $14 \%$ \\
\hline Скорость прорастания семян & 3,1 & 2,1 & 3,7 & 4,6 \\
\hline
\end{tabular}


// Российский журнал прикладной экологии. 2019. - № 1. - С. 53-57.

9. Привалова, Н. М. Определение фитотоксичности методом проростков / Н. М. Привалова [и др.] // Успехи современного естествознания. - 2006. № 10.- С. 45 .

10. Чеснокова, С. М. Биологические методы оценки качества объектов окружающей среды : учеб. пособие. В 2 ч. Ч. 2. Методы биотестирования / С. М. Чеснокова, Н. В. Чугай ; Владим. гос. ун-т. - Владимир : Изд-во ВлГУ, 2008. - 92 с.

11. Шадрина, Е. Г. Биоиндикационная оценка качества среды / Е. Г. Шадрина, В. Ю. Солдатова, В. С. Макаров. - Новосибирск : Наука, 2017. - 240 с.

12. Экологическая оценка городских агломераций на основе индикаторов устойчивого развития / Е. А. Иванцова [и др.] // Вестник Волгоградского государственного университета. Серия 3, Экономика. Экология. - 2019. - Т. 21, № 2. - С. 143156. - DOI: https://doi.org/10.15688/jvolsu3.2019.2.13.

13. Яковишина, Т. Ф. Экотоксикологическая оценка городских почв методом биотестирования / Т. Ф. Яковишина // Universum: химия и биология. 2015. - T. 8, № 16. - C. 14-21.

14. Ecotoxicological Hazard Assessment of Deicing Chemicals for Higher Plants / M. D. Fedorchenko [et al.] // E3S Web of Conferences. Actual Problems of Ecology and Environmental Management: Cooperation for Sustainable Development and Environmental Safety, APEEM. - 2020. - Vol. 169. - Art. 01020. - DOI: https://doi.org/10.1051/e3sconf/202016901020.

15. Heavy Metals in Suburban Ecosystems of Industrial Centres and Ways of Their Reduction / N. V. Onistratenko [et al.] // Ekologia (Bratislava). 2016. - Vol. 35, no. 3. - P. 205-212.

16. Zhuykova, E. V. Genetic Diversity in Local Taraxacum officinale L. Populations from Habitats Varied in Toxic Load/ E. V. Zhuykova, E. R. Zinnatova, I. S. Kiseleva // The Fourth International Scientific Conference Ecology and Geography of Plants and Plant Communities. - Ekaterinburg : Knowledge E, 2018. - C. 243-253. - DOI: https://doi.org/10.18502/ kls.v4i7.3245.

17. Van Dongen, S. The Statistical Analysis of Fluctuating Asymmetry: REMLEstimation of a Mixed Regression Model / S. Van Dongen, G. Molenberghs, E. Matthysen // J. of Evol. Biol. - 1999. - Vol. 12. P. 94-102. - DOI: https://doi.org/10.1046/j.14209101.1999.00012.x.

\section{REFERENCES}

1. GOST 12038-84. Mezhgosudarstvennyj standart. Semena sel'skohozjajstvennyh kul'tur. Metody opredelenija vshozhesti (utv. $i$ vveden $v$ dejstvie Postanovleniem Gosstandarta SSSR ot 19.12.1984 № 4710) (red. ot 01.03.1995. s izm. ot 01.10.1999) [GOST 12038-84. Interstate Standard. Seeds of Agricultural Crops. Methods for Determining Germination (Approved and Put into Effect by the Resolution of the State Standard of the USSR No. 4710 Dated December 19, 1984) (Edited on March 1, 1995, Amended on October 1, 1999)]. URL: http:// www.consultant.ru/search/?q=\% D 0\% $93 \%$ D0\%9E\%D0\%A1\%D0\%A2+12038-84.

2. Ivantsova E.A. et al. Vliyanie prisutstviya podvizhnykh form $\mathrm{Zn}, \mathrm{Cu}$, Ni na funktsionirovanie sistemy «pochva-mikrobiota-rastenie» v zernovykh agrotsenozakh [Influence of the Presence of Mobile Forms $\mathrm{Zn}, \mathrm{Xu}$, Ni on Functioning of the System "SoilMicrobiota-Plant" in Grain Agrocenoses]. Ekologija $i$ promyshlennost Rossii [Ecology and Industry of Russia], 2018, vol. 22, no. 11, pp. 56-59. DOI: https:// doi.org/10.18412/1816-0395-2018-11-56-59.

3. Sazonov V.E. et al., eds. Doklad «O sostojanii okruzhajushhej sredy Volgogradskoj oblasti v 2019 godu» [Report "On the State of the Volgograd Region Environment in 2019"]. Volgograd, TEMPORA Publ., 2020. 300 p.

4. Zaikina V.N., Okolelova A.A., Korchagina M.P. Sposoby transformacii tjazhelyh metallov v pochvah aglomeracii Volgograd-Volzhskij [Methods of Transformation of Heavy Metals in the Soils of the Agglomeration of Volgograd-Volzhsky]. Izvestiia vysshikh uchebnykh zavedenii. Povolzhskii region. Estestvennye nauki [University Proceedings. Volga Region. Natural Sciences], 2018, vol. 2, no. 22, pp. 52-62. DOI: https://doi.org/10.21685/2307-91502018-2-5.

5. Il'in V.B. Tjazhelye metally $i$ nemetally $v$ sisteme pochva-rastenie: monografija [Heavy Metals and Nonmetals in the Soil-Plant System. Monograph]. Novosibirsk, SO RAN, 2012.220 p.

6. Mezhnevskij V.N. Rastenija-indikatory [Plants-Indicators]. Moscow, AST Publ., 2004. 76 p.

7. Plehanova I.O., Zolotarjova O.A., Tarasenko I.D. Primenenie metodov biotestirovaniya pri otsenke ekologicheskogo sostoyaniya pochv [Application of Biotesting Methods in Assessing the Ecological State of Soils]. Vestnik Moskovskogo universiteta. Seriya 17. Pochvovedenie, 2018, no. 4, pp. 36-46.

8. Tunakova Ju.A., Ivanov D.V., Shagidullin A.R., Valiev V.S. Pochvennyj pokrov kak indicator polimetallicheskogo zagrjaznenija prizemnogo sloya atmosfernogo vozduha g. Kazani [Soil Cover As an Indicator of Polymetallic Pollution of the Surface Layer of Atmospheric Air in Kazan]. Rossijskij zhurnal prikladnoj ekologii, 2019, no. 1, pp. 53-57.

9. Privalova N.M., Procaj A.A., Litvinenko Ju.F., Marchenko L.A, Pan'kov V.A. Opredelenie 
fitotoksichnosti metodom prorostkov [Determination of Phytotoxicity by the Method of Seedlings]. Uspehi sovremennogo estestvoznanija, 2006, no. 10, p. 45.

10. Chesnokova S.M., Chugaj N.M. Biologicheskie metody ocenki kachestva obyektov okruzhayushhey sredy: ucheb. posobie. V 2 ch. Ch. 2. Metody biotestirovanija [Biological Methods for Assessing the Quality of Environmental Objects. Textbook in 2 Parts. Part 2. Methods of Biotesting]. Vladimir, Izd-voVlGU, 2008. 92 p.

11. Shadrina E.G., Soldatova V.Ju., Makarov V.S. Bioindikacionnaja ocenka kachestva sredy [Bioindicational Assessment of Environmental Quality]. Novosibirsk, Nauka Publ., 2017.240 p.

12. Ivantsova E.A., Postnova M.V., Sagalaev V.A., Matveeva A.A., Kcholodenko A.V. Ekologicheskaja ozenka gorodskich aglomerazij na osnove indikatorov ustoichevogo razvitija [The Environmental Assessment of Urban Agglomerations on the Basis of Sustainable Development Indicators]. Vestnik Volgogradskogo gosudarstvennogo universiteta. Seriya 3, Ekonomika. Ekologiya [Science Journal of Volgograd State University. Global Economic System], 2019, vol. 21, no. 2, pp. 143-156. DOI: https://doi.org/10.15688/jvolsu3.2019.2.13.

13. Jakovishina T.F. Ekotoksikologicheskaya ocenka gorodskih pochv metodom biotestirovaniya [Ecotoxicological Assessment of Urban Soils by
Biotesting Method]. Universum: himiya i biologiya, 2015, vol. 8, no. 16, pp. 14-21.

14. Fedorchenko M.D., Mikhaylichenko K.Y., Adarchenko I.A., Ushakova O.V. Ecotoxicological Hazard Assessment of Deicing Chemicals for Higher Plants. E3S Web of Conferences. Actual Problems of Ecology and Environmental Management: Cooperation for Sustainable Development and Environmental Safety, APEEM, 2020, vol. 169, art. 01020. DOI: https://doi.org/10.1051/e3sconf/202016901020.

15. Onistratenko N.V., Ivantsova E.A., Denysov A.A., Solodovnicov D.A. Heavy Metals in Suburban Ecosystems of Industrial Centres and Ways of Their Reduction. Ekologia (Bratislava), 2016, vol. 35, no. 3, pp. 205-212.

16. Zhuykova E.V., Zinnatova E.R., Kiseleva I.S. Genetic Diversity in Local Taraxacum officinale L. Populations from Habitats Varied in Toxic Load. The Fourth International Scientific Conference Ecology and Geography of Plants and Plant Communities. Ekaterinburg, Knowledge E, 2018, pp. 243-253. DOI: https://doi.org/10.18502/kls.v4i7.3245.

17. Van Dongen S., Molenberghs G., Matthysen E. The Statistical Analysis of Fluctuating Asymmetry: REML Estimation of a Mixed Regression Model. J. of Evol. Biol., 1999, vol. 12, pp. 94-102. DOI: https:// doi.org/10.1046/j.1420-9101.1999.00012.x.

\section{Information About the Authors}

Nikolay V. Onistratenko, Candidate of Sciences (Biology), Associate Professor, Department of Ecology and Nature Management, Volgograd State University, Prosp. Universitetsky, 100, 400062 Volgograd, Russian Federation, onistratenko@volsu.ru

Xenia I. Roubanova, Student, Department of Ecology and Nature Management, Volgograd State University, Prosp. Universitetsky, 100, 400062 Volgograd, Russian Federation, econecol@volsu.ru

\section{Информация об авторах}

Николай Владимирович Онистратенко, кандидат биологических наук, доцент кафедры экологии и природопользования, Волгоградский государственный университет, просп. Университетский, 100, 400062 г. Волгоград, Российская Федерация, onistratenko@volsu.ru

Ксения Игоревна Рубанова, студент кафедры экологии и природопользования, Волгоградский государственный университет, просп. Университетский, 100, 400062 г. Волгоград, Российская Федерация, econecol@volsu.ru 